\title{
Expert assessment of animal infectious pathology nosological profile boundaries in a specific agroclimatical zone
}

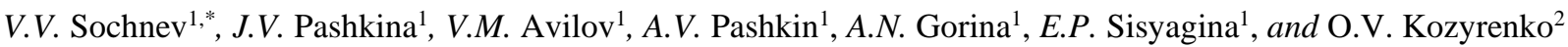 \\ ${ }^{1}$ Nizhny Novgorod State Academy of Agricultural Sciences, 603107 Nizhniy Novgorod, Russia \\ ${ }^{2}$ Saint-Petersburg State Academy of Veterinary Medicine, 196084 Saint-Petersburg, Russia
}

\begin{abstract}
Functioning of 51 parasitic systems has been retrospectively ascertained in the South-Eastern agroclimatic zone of Nizhny Novgorod Oblast, their co-agents, apart from their excitants, being productive and non-productive domestic and wild animals. For the entire depth of retrospection ( 82 years) eleven nosounits of infectious pathology in the region $(21.6 \%)$ dominated in the quantity of epizootic foci and diseased animals (rabies, dictyocaulosis, infectious atrophic rhinitis, classical pig plague, pyroplasmosis, salmonellosis, swine erysipelas, anthrax, fasciolasis, blackleg, aphtha). They accounted for 241 episootic foci in the nosological profile of infectious pathology $(68.5 \%$ of the total quantity of animal infectious disease epizootic foci in the region throughout the retrospection). At the same time, 13 nosounits in the investigated territory were registered only once during the entire period of retrospection, no expansion of the boundaries of their epizootic manifestation was ascertained, and carryover of the excitant of these infectious diseases beyond the limits of the original epizootic focus was prevented. Relapses of their epizootic occurrences in the region were prevented as well. Ten nosounits of animal infectious pathology (18\%) in the aggregate animal pathology in the examined region during the entire period of retrospection were registered twice (hen typhus, swine and cattle taeniasis, swine metastrongylosis, contagious cattle rhinotracheitis, hen ascaridiasis, cattle parainfluenza, bee nosematosis). In addition, potential danger of animal infectious pathology spontaneous emergence and expansion was revealed in the South-Eastern zone of Nizhny Novgorod Oblast (anthrax, blackleg, cattle tuberculosis, fasciolasis, classical and African pig plague, pyroplasmosis, echinococcosis, rabies). Schematic models of the biological hazard epizootic component potential threat in the region have been designed. New scientific data have been obtained about the epizootic condition dynamics of rural and urban territories in the region as a biological hazard epizootological component, about regional peculiarities of animal infectious pathology specific nosounits, about their potential epidemic danger in the region.
\end{abstract}

\section{Introduction}

Biological hazard in specific regions of Russia, just as in other countries, is formed with consideration of the epizootic component, i.e. the set of animal nosounits (diseases) that simultaneously pose a threat to animals and humans. [1, 2].

An animal infectious pathology nosological profile always has its regional peculiarities and, as a rule, is due to the geographical range of specific infections and invasions excitants [3].

In the second half of the last century a theory of infectious parasitic systems formation and functioning about the evolution of parasite-host relations was made public in Russia [3-5].

According to the example of specific contagious diseases there formed a theory of epidemic (epizootic) process self-regulation. The theory was supported by native researchers and it practically proved to be a continuation of I.V. Davydovskiy's teaching about causation in medicine [6].
It is believed that all types of infections constitute a phenomenon that formed on the basis of parasitism, and that all excitants of infectious animal diseases ought to be considered as pathogen-parasites inhabiting an animal or human organism, causing considerable harm to it (by force of pathogenicity factors) [7-10].

S.I. Dzhupina and his disciples [3] developed and presented a theory of the epizootic process, upon which they examine the regularities of parasite-host relation formation and infectious parasitogenic system formation.

Many native researchers share and support the teaching about parasitogenic systems and about epizootic process self-regulation.

For instance, V.V. Makarov with his co-authors [7] consider V.D. Belyakov's teaching to be a paradigm of modern biological and medical science, fully catering to the needs of modern epidemiology and epizootology. On the platform of evidence-based epizootology methods, they deciphered the regularities of the epizootic process of specific nosounits in practical medical and veterinary sciences.

\footnotetext{
* Corresponding author: kafedra40@mail.ru
} 
In the conditions of globalization many countries are facing the epizootic manifestation of cross-border, emergent infections caused by a carryover of excitants into new territories, into new animal populations.

According to researchers, this is promoted by technogeneous and energetical influences on productive and non-productive animal population co-members, generating a discomfort of their organism with the habitat, reducing their natural resistance to excitant-parasite pathogenic influence. In these circumstances currently it remains important to investigate the regional peculiarities of infectious animal pathology nosological profile formation as a biological hazard epizootological component.

Research purpose is to study the biological safety of epizootological component over time and in the comparative aspect in the South-Eastern zone of the Volga region (by the example of Nizhny Novgorod region) and on this basis to give proposals on optimizing the antiepizootic system in the region.

\section{Materials and methods}

The epizootological geography of animal infectious disease dominating nosounits in the South-Eastern part of Nizhny Novgorod Oblast, epizootological parameters of productive animal populations, preconditions and dynamic positions of their aggregate infectious pathology, changes of its nosological profile, epizootic and epidemic projection of the most commonly occurring contagious and invasive animal diseases in the region have been studied on the basis of operative and retrospective epizootological analysis of the results of clinical epizootological researches and examinations of epizootic foci and problematic sites, as well as on the basis of analysis of veterinary records and reports on animal infectious and non-infectious pathology at the branch offices of the academic department of epizootology, parasitology and veterinary sanitary expert assessment of the Nizhny Novgorod State Academy of Agricultural Sciences. Generally available materials of the regional directorates of the Federal Service for Veterinary and Phytosanitary Surveillance and Federal Service for Supervision of Consumer Rights Protection and Human Welfare have been used in the work.

The methodical solutions are based on the comprehensive epizootological approach (V.P. Urban and others, 1991), clinical epizootological, pathological morphological, bacteriological, virological, biochemical, haematological, statistical, cartographical researches carried out on certified equipment at the Nizhny Novgorod Oblast and Arzamas transregional veterinary laboratories.

Retrospective epizootological analysis of the epizootic situation in the conditions of a specific administrative district was performed on the accessible depth of retrospection using epizootic journals for the years of 1935 through 2017.

The cause-and-effect relations of the changes in the epizootic situation in the region were studied by way of forming and checking hypotheses based on the results of polyfactorial analysis of multi-year and one-year dynamics of specific nosounit epizootic manifestation. The territorial application boundaries of epizootic manifestation timeframe and population limits in the region of infectious and invasive parasitogenic systems were investigated using evidence-based epizootology methods (V.V. Sochnev, J.V. Pashkina), modern prognostics (V.A. Lisichkin, 1972 [11]) and statistical quality control (N.A. Plokhinskiy, 1980 [12]; Hitoshi Kume, 1990 [13]).

The efficiency of anti-epizootic provisions was examined in cooperation with specialists of the State Veterinary Supervision Committee, territorial directorate of the Federal Service for Veterinary and Phytosanitary Surveillance for Nizhny Novgorod Oblast and the Mari El Republic in the comparative aspect and in real time by the method of expert assessment of materials on the Pervomaiskiy District of Nizhny Novgorod Oblast.

The optimization of the system of anti-epizootic provisions for the regional agrarian business, rural and urban territories and its implementation were conducted in liaison with specialists of the State Veterinary Supervision Committee of Nizhny Novgorod Oblast with consideration of the results of our research and their approbation.

\section{Results and discussion}

The nosological profile of productive animal infectious pathology in the South-Eastern zone of Nizhny Novgorod Oblast was studied using a digital technology and presented for each nosounit with problematicity, focality, epizooticity index, incidence and prevalence, death rate and lethality parameters and it was ascertained that 11 nosological forms $(21.6 \%$ of their total quantity in the region) constantly and 3 nosounits intermittently (5.9\%) dominated in the region for the entire depth of retrospection (table 1).

It was ascertained that the nosounits dominating in the nosological profile of animal infectious pathology in the district accounted for 261 epizootic foci (74.1\% of the total quantity of all nosounits' epizootic foci), on average $18.6 \pm 4.3$ epizootic foci per one nosounit, or 3.4 times more than the average parameter for all animal infectious diseases in the region under study. The epizootic manifestation of these parasitogenic systems is distinguished by a pronounced variability of focality from 1.05 in case of brucellosis to 53.6 in case of classical pig plague, territorial application and epizooticity index. A schematic model of nosounits' domination in the region was designed and presented in digital form (fig. 1).

The analysis of the Pareto diagram shows that 11 nosounits in the nosological profile of infectious pathology $(21.6 \%$ of the total quantity of nosounits) constantly dominate in the quantity of epizootic occurrences (they account for $62.9 \%$ of all epizootic foci in the region).

During the analyzed period (82 years) 15321 animals fell ill with infectious diseases, on average $300.4 \pm 15.0$ diseased animals per one nosounit, with a high fatality rate $(9.4 \%)$. For some of the diseases the focality level of a specific nosounit reached 1178.8 diseased animals per one epizootic focus (in case of hen coccidiosis), in case 
of cattle rhinotracheitis (353.0), parainfluenza-3 (483 diseased animals per 1 epizootic focus), swine viral gastroenteritis (513).

Our data on the focality of animal infectious pathology specific nosounits in the district have been obtained for the first time ever. Based on the obtained research results a schematic model of animal infectious disease focality in the region was developed by digital technolo- gy methods. It was confirmed that the focality of hen coccidiosis was 29 times higher than the average focality parameter for all animal infectious diseases in the region, in case of rhinotracheitis, cattle parainfluenza-3 and swine viral gastroenteritis - 8.1, 11.1, 11.7 times higher respectively.

Table 1. Digital technology of studying the dominating nosounits in the nosological profile of productive animal infectious pathology in the South-Eastern zone of Nizhny Novgorod Oblast, years of 1935-2017

\begin{tabular}{|c|l|c|c|c|c|c|c|c|c|}
\hline $\begin{array}{c}\text { S1. } \\
\text { № }\end{array}$ & \multicolumn{1}{|c|}{ Nosounit } & $\begin{array}{c}\text { Quantity } \\
\text { of epizo- } \\
\text { otic foci } \\
\text { for the } \\
\text { entire } \\
\text { period }\end{array}$ & $\begin{array}{c}\text { In to } \\
\text { the total } \\
\text { qty of } \\
\text { epizootic } \\
\text { foci }\end{array}$ & Fallen ill & Focality & $\begin{array}{c}\text { Problema- } \\
\text { ticity pa- } \\
\text { rameter }\end{array}$ & $\begin{array}{c}\text { Epizooticity } \\
\text { index }\end{array}$ & $\begin{array}{c}\text { Death rate, } \\
\%\end{array}$ & $\begin{array}{c}\text { Unfavourable } \\
\text { outcome }\end{array}$ \\
\hline 1 & Pyroplasmosis & 34 & 9.7 & 131 & 5.46 & 0.246 & 0.319 & 9.9 & 9.9 \\
\hline 2. & Dictyocaulosis & 33 & 9.4 & 1633 & 43.5 & 0.292 & 0.195 & 0.6 & 0.6 \\
\hline 3. & Rabies & 32 & 9.1 & 33 & 1.05 & 0.492 & 0.756 & 72.1 & 97.0 \\
\hline 4. & Swine erysipelas & 20 & 5.7 & 135 & 9.75 & 0.138 & 0.305 & 37.5 & 37.5 \\
\hline 5. & Anthrax & 18 & 5.1 & 24 & 1.3 & 0.276 & 0.158 & 66.7 & 100.0 \\
\hline 6. & Blackleg & 15 & 4.3 & 33 & 2.2 & 0.231 & 0.183 & 100 & 100.0 \\
\hline 7. & Salmonellosis & 16 & 4.5 & 357 & 22.3 & 0.189 & 0.643 & 24.4 & 24.4 \\
\hline 8. & Fasciolasis & 19 & 5.4 & 72 & 3.79 & 0.200 & 0.085 & - & - \\
\hline 9. & $\begin{array}{l}\text { Infectious atrophic } \\
\text { rhinitis }\end{array}$ & 13 & 3.7 & 102 & 7.85 & 0.123 & 0.110 & - & 100 \\
\hline 10. & Aphtha & 12 & 3.4 & 491 & 40.3 & 0.185 & 0.317 & - & 0.2 \\
\hline 11. & Classical pig plague & 9 & 2.3 & 452 & 53.6 & 0.108 & 0.061 & 30.5 & 98.7 \\
\hline 12. & Hen tuberculosis & 22 & 6.3 & 727 & 33.05 & 0.338 & 0.134 & 8.8 & 13.4 \\
\hline 13. & Cattle tuberculosis & 8 & 2.3 & 31 & 3.9 & 0.623 & 0.097 & - & 48.4 \\
\hline 14. & Gangrenous coryza & 10 & 2.8 & 34 & 3.4 & 0.153 & 0.073 & 94.1 & 92.1 \\
\hline & & $261 *$ & 74.1 & - & & & & & \\
\end{tabular}

* Note: The number 261 includes 22 epizootic foci of hen tuberculosis, 8 epizootic foci of cattle tuberculosis and 10 epizootic foci (sporadic occurrences) of gangrenous coryza (revealed in the years of 1950, 1954-1964), which have not been registered in the region under study during the last 53 years.

The territorial boundaries of dominating animal infectious diseases in the region were studied by methods of evidence-based epizootology, and it was ascertained that their problematicity parameter varied from 0.008 (in case of classical pig plague in the years 1956-1961) to 0.492 (in case of rabies infection in the years 19522014). Based on the obtained results a digital schematic model of specific nosounit territorial boundaries in the region was developed (fig. 2).

It was confirmed that the problematicity level for 14 (28\%) nosounits constituted 0.015 , for others - 14 (28\%) - from 0.031 to 0.046 ; for 12 nosounits (24\%) from 0.062 to 0.123 ; four nosounits $(8 \%)$ were encountered in 15.4 to $18.9 \%$ of the district territory, three nosounits $(6 \%)$ - in $19.5-24.6 \%$ of the territory respectively. The broadest territorial boundaries of epizootic manifestation application in the district have been ascertained in case of animal rabies -0.492 .
At the same time the epizooticity index of each animal pathology nosounit presented in the nosological profile was investigated. The highest epizooticity index was found in case of paratyphoid and colibacteriosis in feeder cattle (0.634), i.e. during the entire period of retrospection (82 years) 52 years were problematic in this disease, virtually yearly from 1954 to 2006.

An even higher epizooticity index in the district was found in case of rabies infection (0.756) (from 1952 to 2014 the district remained problematic in this animal disease), as well as in case of infectious anaemia (0.890) and other animal diseases. By methods of evidencebased epizootology for the first time ever we succeeded in calculating and presenting a digital model of the territory epizootology and epizooticity index practically for all animal infectious diseases. 


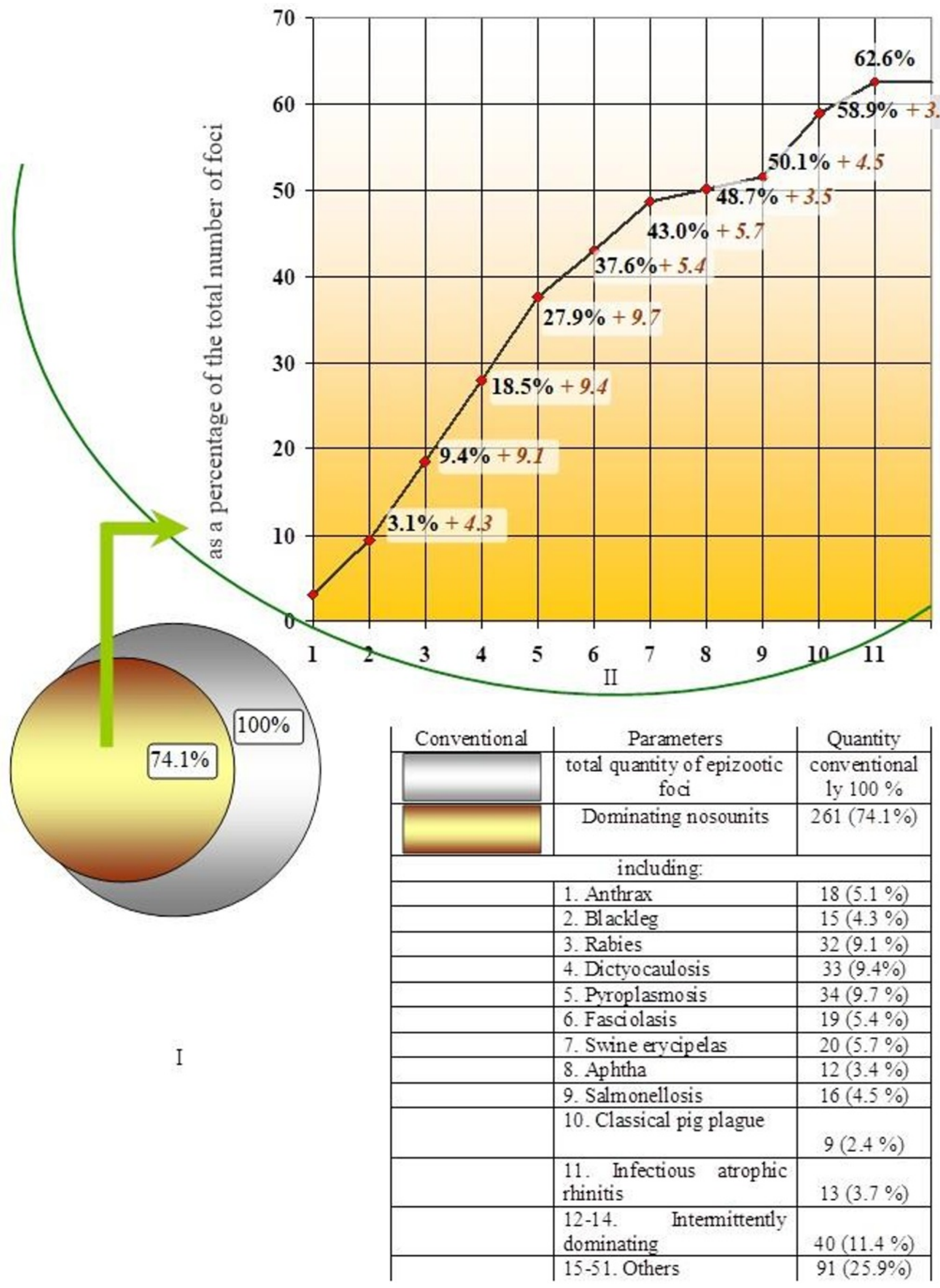

Fig. 1. Schematic model (Pareto diagram) of animal infectious pathology nosounit domination in the conditions of the South-Eastern region of Nizhniy Novgorod Oblast (by the quantity of nosounit epizootic foci registered from 1935 to 2017) 


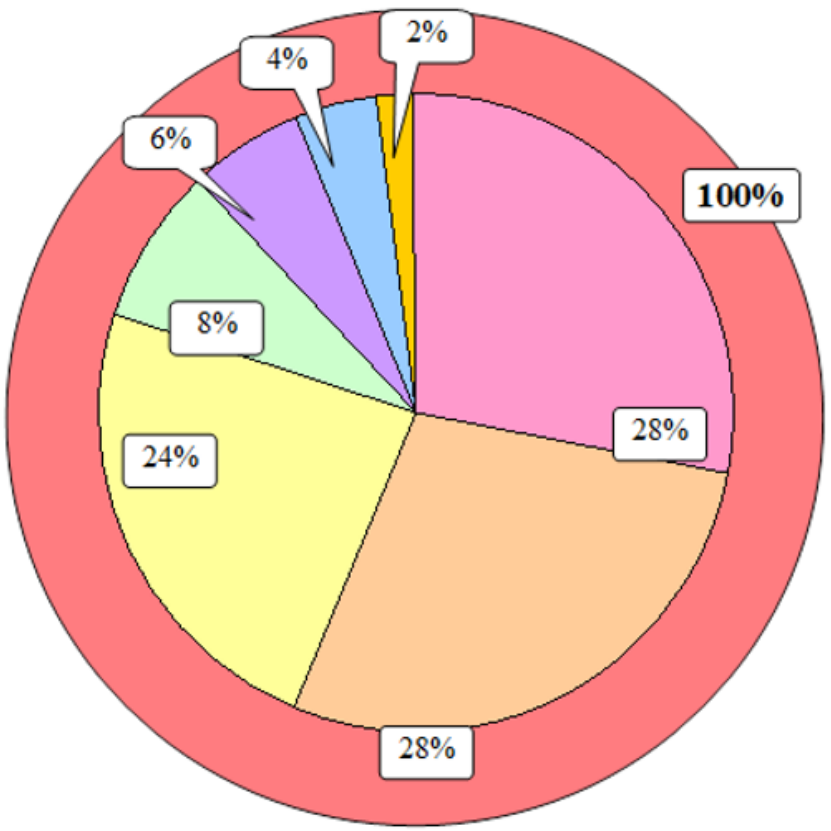

\begin{tabular}{|l|c|c|}
\hline Conventional symbols & Parameters & Quantity, \% \\
\hline & Aggregate infectious pathology & Conventionally $100 \%$ \\
\hline & $\begin{array}{c}\text { including with problematicity } \\
\text { parameter up to } 0.015\end{array}$ & $28 \%$ \\
\hline & $\begin{array}{c}\text { including with problematicity } \\
\text { parameter } 0.031-0.046\end{array}$ & $24 \%$ \\
\hline & $\begin{array}{c}\text { including with problematicity } \\
\text { parameter } 0.062-0.123\end{array}$ & $6 \%$ \\
\hline & $\begin{array}{c}\text { including with problematicity } \\
\text { parameter } 0.154-0.189\end{array}$ & $2 \%$ \\
\hline & $\begin{array}{c}\text { including with problematicity } \\
\text { parameter } 0.195-0.246\end{array}$ & $2 \%$ \\
\hline & $\begin{array}{c}\text { including with problematicity } \\
\text { parameter } 0.276-0.292\end{array}$ & $2 \%$ \\
\hline & $\begin{array}{c}\text { including with problematicity } \\
\text { parameter } 0.354-0.492 \uparrow\end{array}$ & \\
\hline
\end{tabular}

Fig. 2. Digital schematic model of animal infectious pathology epizootic manifestation application territorial boundaries in the region under study for the period of 1935-2017

We investigated the duration of epizootic occurrence functioning for all the animal infectious pathology nosounits in the region under study. The quantitative measurement of this parameter was performed by way of determining the epizooticity index accepted in evidencebased epizootology. For all quarantine infections we took the calendar dates of introducing and raising quarantine (limitations) as the duration of epizootic manifestation timeframe.

We have ascertained that the average (aggregate) epizooticity index calculated for the entire period of retrospection ( 82 years) is 0.135 , or 11 years. However, for some of the nosounits it was much lower (0.012), for others it reached an incredibly high value $(0.756$ - for rabies and 0.305 - for swine erycipelas).

Based on the obtained research results we have developed a schematic model of the animal infectious pathology epizootic manifestation timeframe (fig. 3) and confirmed that the time of parasitogenic system epizootic functioning in the region is quite controversial. In some cases the epizooticity index for epizootic nosounits is quite low, whereas for others - it exceeds permissible limits.

For instance, 4 nosounits were found prone to a long duration of the epizootic manifestation in the region (monieziasis, swine erycipelas, cattle pyroplasmosis), other nosounits (rabies, paratyphoid, colibacteriosis, infectious anaemia, cattle gangrenous coryza) - to stationariness and movable territorial application boundaries. The obtained research results have a pronounced applicative value and are considered when optimizing the anti-epizootic provisions of the region.

We have performed a retrospective analysis of the disease process progress of morbidity in case of an epizootic manifestation of animal infectious diseases in the region and their outcome in animal populations. We rec- 
orded and analyzed the infectious process morbidity parameters by the calculated and investigated by us fatality rate of the co-members of animal populations against the background of their enduring infectious diseases.

The outcome of an epizootic process in every specific focus was recorded by its subsidence and by the aggregate fatality parameter and forced animal slaughter in an epizootic focus (unfavorable outcome). For visualization of the research results the nosological units were grouped by the value of the fatality parameter (fig. 4) and by the value of unfavorable outcomes during the functioning of epizootic foci (fig. 5).
We have confirmed that by constructing schematic models of infectious pathology nosounit epizootic focus functioning fatality and unfavorable outcomes in the territory of the region under study one can not only visualize the business and social consequences of animal infectious pathology manifestation in the district and adjacent territories, but also open unused reserves in organizing highly efficient anti-epizootic provisions for animal breeding and biological safety of rural and urban territories in the modern context.

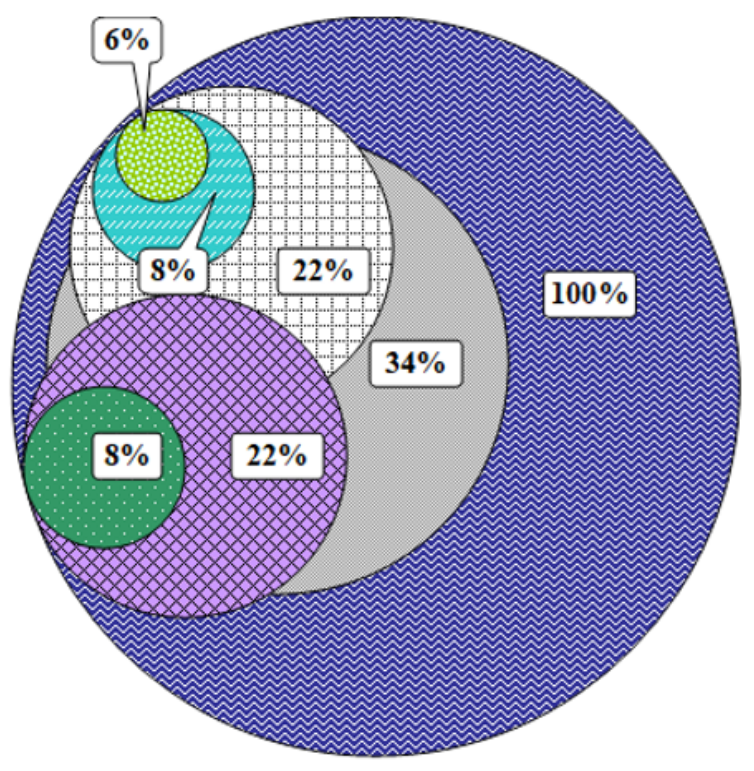

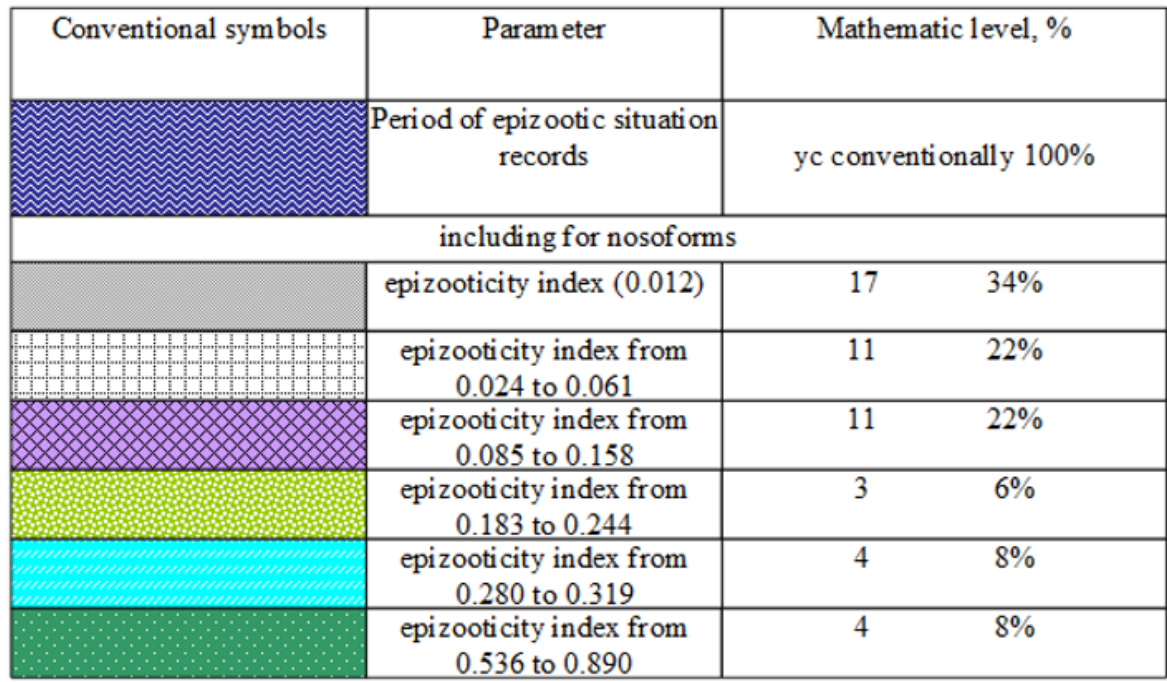

Fig. 3. Digital technology of constructing a linear-graphical schematic model of infectious and invasive parasitogenic system epizootic manifestation timeframe in the conditions of the South-Eastern zone of Nizhny Novgorod Oblast, the years of 1935-2017 

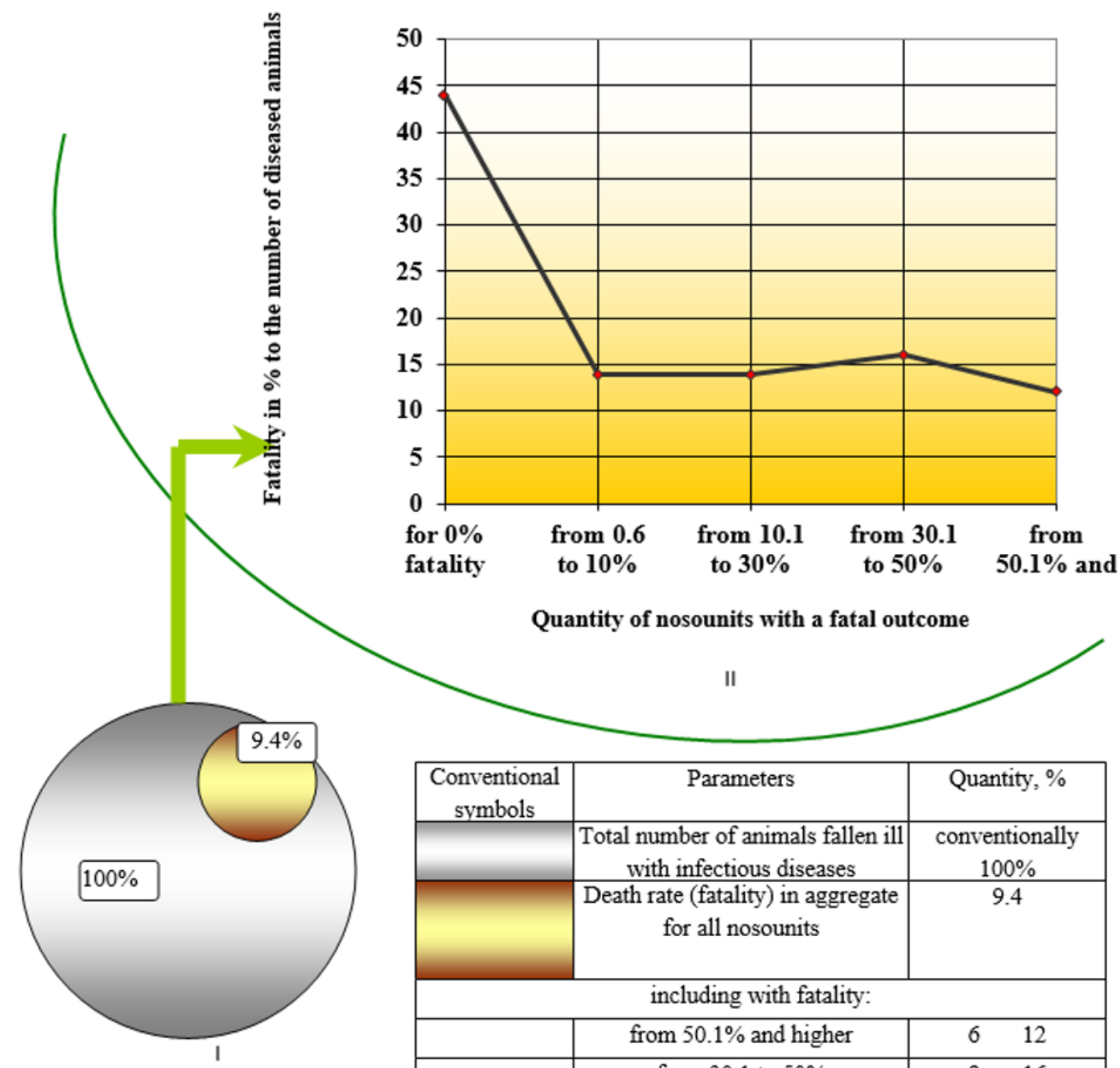

Quantity of nosounits with a fatal outcome

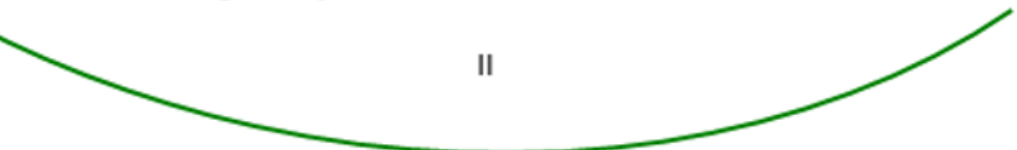

\begin{tabular}{|c|c|cc|}
\hline $\begin{array}{c}\text { Conventional } \\
\text { symbols }\end{array}$ & Parameters & Quantity, \% \\
\hline & $\begin{array}{c}\text { Total number of animals fallen ill } \\
\text { with infectious diseases }\end{array}$ & $\begin{array}{c}\text { conventionally } \\
100 \%\end{array}$ \\
\hline & $\begin{array}{c}\text { Death rate (fatality) in aggregate } \\
\text { for all nosounits }\end{array}$ & \multicolumn{2}{c|}{9.4} \\
\hline & \multicolumn{3}{|c|}{ including with fatality: } \\
\hline & from $50.1 \%$ and higher & 6 & 12 \\
\hline & from 30.1 to $50 \%$ & 8 & 16 \\
\hline & from 10.1 to $30 \%$ & 7 & 14 \\
\hline & from 0.6 to $10 \%$ & 22 & 44 \\
\hline & without animal death & 74 \\
\hline
\end{tabular}

Fig. 4. Digital technology of constructing a schematic model of animal population co-member fatality parameters in epizootic foci functioning in the infectious pathology nosounits region, the years of 1935-2017 


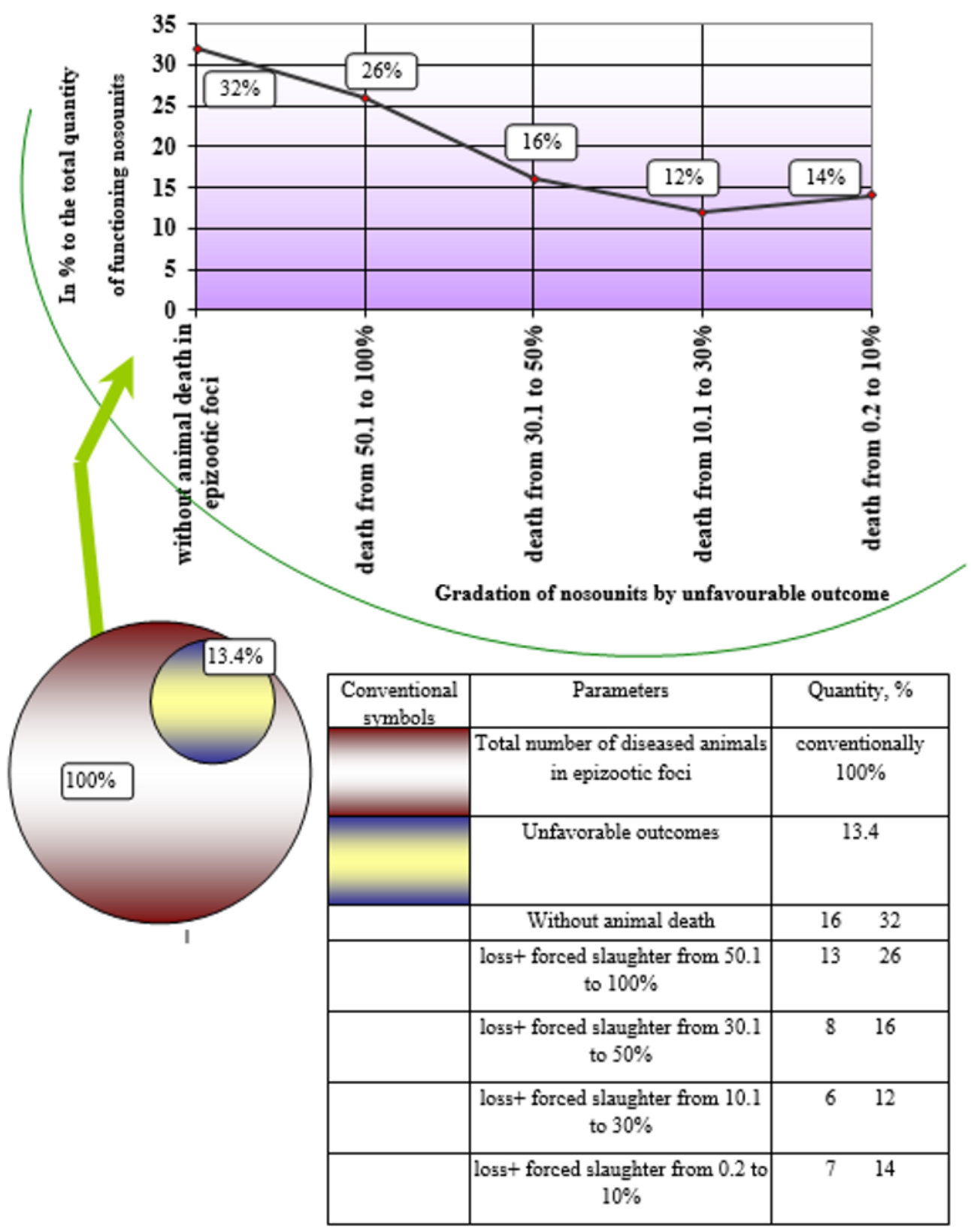

Fig. 5. Digital technology of constructing a schematic model of the consequences of infectious and invasive parasitogenic systems epizootic functioning in the South-Eastern zone of Nizhny Novgorod Oblast, the years of 1935-2017

\section{Conclusion}

Based on the performed research and expert assessment of the results of studying the epizootic manifestation of the infectious pathology of agricultural, domestic nonproductive and wild animals in the conditions of the South-Eastern zone of Nizhny Novgorod Oblast we have ascertained that during the analyzed period here constantly or intermittently functioned with various degrees of extensity and intensity 51 infectious and invasive parasitogenic systems, giving rise both to single epizootic foci and to a wide spread across the territory and in animal populations. On average each nosounit of infectious pathology for the last 82 years accounts for $6.9 \pm 1.5$ epizootic foci.
Out of the total quantity of registered infectious pathology nosounits $11(21.6 \%)$ were functioning on a permanent basis, 3 were intermittently dominating in the nosological profile, manifesting a trend both for territorial application. More than $10 \%$ of the animal infectious pathology incidents in the region ended with an unfavorable outcome.

The research results have allowed carrying out epizootological prognostication of an epizootic situation based on digital technologies and to perform scientifically-grounded optimization of anti-epizootic provisions of rural and urban territories, which was conducive to implementing a system of epizootic process control on the animal infectious pathology nosounits dominating in the region. 


\section{References}

1.V.S. Buzlama, Stress and its prevention in industrial cattle breeding, Raising agricultural animal productivity and prevention of their diseases in agrarian businesses, 6 (part III), 36-39 (Voronezh, 1990)

2. O.A. Verhovsky, A. Kh. Naymanov, O.A. Savitskaya, Yu.N. Fedorov, N.P. Ovdienco, J.D. Collins, Evaluation of the Single intramedial Tuberculin test and the commertial-interferon assay for the detection of M. bovis infected cattle in Russia, in $6^{\text {th }}$ Int. Veterinary Immunology Symp., 174 (Swedish University of Agriculture Sciences, Upsalla, 15-20 July 2001)

3.S.I. Dzhupina, Methods of epizootological research and theory of epizootic process (Nauka, Siberian subdivision, Novosibirsk, 1991)

4. V.D. Belyakov, Contemporary views on carriage of infectious disease excitants and its meaning in the development of an epidemic process, in Carriage of bacteria and chronical forms of infectious diseases. Theses of All-Union Sci. Conf., Part 1, 21-34 (Moscow, 1975)

5. V.D. Belyakov, A.P. Degtyarev, Y.G. Ivannikov Quality and efficiency of anti-epidemic measures (Moscow, 1981)

6. I.V. Davydovskiy, Teachings about infection (biological aspect of the problem) (Moscow, Medicine, 1956)
7.V.V. Makarov, The theory of parasitogenic systems self-regulation by V.D. Belyakov is a paradigm in the teaching about the epidemic process, Veterinary pathology, 3(10), 10-13 (2004)

8. A.V. Pashkin et al., Major co-agents of formed parasitogenic systems in the Lower Volga region, Veterinary practice, 3(38), 28-21 (Saint Petersburg, 2007)

9. V.V. Sochnev, V.M. Avilov, N.V. Philippov, Territory, time and population limits of the epizootic process of brucellosis in the conditions of Volgograd Oblast, in 100 th anniversary of the Kursk biofactory and agrobiological industry of Russia: Theses of the sci. industrial conf. report, 310-311 (Kursk, 1996)

10. V.V. Sochnev, V.P. Urban, N.V. Philippov, Prognostic diagnosis of cattle brucellosis epizootic process in zones with various disease risk degrees in the conditions of Volgograd Oblast: Scientific Report of Nizhny Novgorod State Academy of Agricultural Sciences №395 (N. Novgorod, 1994)

11. V.A. Lisichkin, Theory and practice of prognostics (Moscow, 1972)

12. N.A. Plokhinskiy, Biometrics algorithms (Moscow State University, Moscow, 1980)

13. Hitoshi Kume, Statistical methods of quality improvement (Moscow, 1990) 